\title{
WALKING FEEDER MODE SERVICES CHOICE ANALYSIS FOR INTEGRATION OF BUS RAPID TRANSIT SYSTEM: A CASE STUDY
}

\author{
Manjurali Imadadali Balya ${ }^{1}$, Rakesh Kumar ${ }^{2}$ \\ ${ }^{1,2}$ Sardar Vallabhbhai National Institute of Technology, Surat, India
}

Received 9 August 2017; accepted 2 October 2017

\begin{abstract}
Public transit system plays a vital role in economic development for access to the commuters in urban locations. To ensure accessibility of public transit system is a daunting task faced by developing countries due to the lack of feeder services. The present study examines research on proposed feeder mode service choices as walking as one mode with three optional service categories such as Exclusive Footpath Service (EFS), Special Shoulder Treatment for Pedestrian only (SSTP) and Pedestrian allow in Mixed Traffic (PMT) services. The Multinomial Logit (MNL) Model is used to analyze the proposed integrated services for Bus Rapid Transit System corridor of Ahmedabad City in SPSS environment. The findings revealed the increase in travel time and travel distance causes the user's choice decrease to the proposed services and shift to personal vehicles for access to the stops. The prediction accuracy of the proposed model is $49.4 \%$ which is greater than the proportional by chance accuracy criteria of $47.9 \%$ indicates the model was satisfied. The output of this research paper is based on case study, but the proposed methodology can apply as base for introducing the proposed walking feeder mode services of the same sized metropolitan cities.
\end{abstract}

Keywords: integrated walking feeder mode services, walking, bus rapid transit system (BRTS), multinomial logit (MNL) model.

\section{Introduction}

Due to the lack of access to the transit bus stop often the users prevents a large section of society from using the bus in Asian developing countries. This problem professed as the unavailability of access/ egress transport connectivity to the transit bus stops. Accessibility to transit stop can often solve the issue of first/last mile connectivity (Chandra et al., 2013). The integrated feeder service approach can be beneficiated to society for reducing the accessibility problems. It can be made the public transport attractive, regarding mobility, easy access, convenience, and comfort to the commuters (Martínez and Eiró, 2012). Integrated feeder services reduce the total travel time of the commuters/ travelers, as well as the journeys made by intermediate public transport services and personal vehicles which are the direct impact on the reduction of congestion, delays, and environmental pollution to a right level (Verma and Dhingra, 2005). Many past attempts have been made to integrated feeder services with the public transit system (Balya and Kumar, 2017; Chandra et al., 2013; Chien and Yang, 2000; Das et al., 2012; Mohaymany and Gholami, 2010; Rahman et al., 2012; Shrivastava and O'Mahony, 2006; Verma and Dhingra, 2005).

${ }^{1}$ Corresponding author: mibalya.civil@spcevng.ac.in 
Many of the past literature studies on public transport have shown that walking is the most natural and necessary access mode to public transport (Cervero, 2001; Loutzenheiser, 1997; Stringham, 1982; Wibowo and Olszewski, 2005). Walking are the most favorable mode if the built environment around the stop is contributing to these modes and over the years. Walking has seen a well amount of popularity relatively because of the health benefits associated with it (Replogle, 1992). Walking accessibility to public transport is applied to indicate the quality or performance of public transport service (Polzin et al., 2000; Rudnicki, 1999; Wibowo and Olszewski, 2005). In recent public transport studies, public transport accessibility is connected with a particular number that is related to walking distance or walking time (Wibowo and Olszewski, 2005).

The objective of this research is to develop proposed integrated walking feeder mode services choice modeling of Viratnagar to Naroda BRTS (Bus Rapid Transit System) corridor of Ahmedabad city using completely disaggregated data. The home interview survey was carried out to collect the data as face to face technique, to know the socioeconomic characteristics and the behavior of commuters/travelers towards walking feeder mode services choice of proposed integrated service. The explanatory variables included in the models are the demographic and socioeconomic characteristics of individuals, trip/travel characteristics, and model attributes. The MNL model was used to identify significant factors to predict the probability of a change in feeder mode services choice of proposed integrated walking mode.

\section{Proposed Integrated Walking (Pedestrian) Network}

The proposed integrated walking (Pedestrian) network has developed based upon the walking taken as feeder mode with three service categories viz. Exclusive Sidewalk (ESW), Special Shoulder Treatment for Pedestrian only (SSTP) and Pedestrian allow in Mixed Traffic (PMT). The BRT service at the origin (destination side does not consider for this study) is linked with proposed integrated walking (Pedestrian) feeder services shown in Fig. 1. These services mainly provided at access trips only. Here this research paper is by case study only. The reality of the available existing walking services and the proposed walking feeder services categories are shown in Fig. 2.

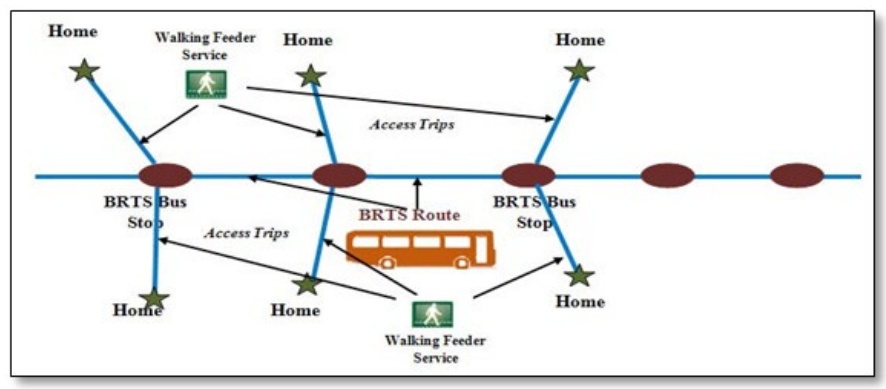

Fig. 1.

Integrated Walking (Pedestrian) Network of BRTS Route 




Fig. 2.

Proposed Integrated Walking (Pedestrian) Feeder Service Categories on BRTS Route

\section{Methodology and Data Preparation}

The proposed disaggregate model was developed based on the combination of a revealed preference $(\mathrm{RP})$ and stated preference (SP) survey, conducted to study the commuter's socioeconomic characteristics, present travel characteristics and their willingness to change to the proposed walking feeder mode choice services of BRTS. The data set is collected by Home Interview Survey (HIS) using face to face technique radially around the residential area of Viratnagar to Naroda Patiya corridor of BRTS of Ahmedabad city with the appropriately structured questionnaire format. The surveys carried out by eight-member team (Undergraduate students) who knocked on doors during various times of the day and done in person interviews. The questions were arranged based on significance to the respondents' experiences and trip information. This questionnaire comprises of the revealed preference data such as a description of travel (such as travel mode, the purpose of trip, origin \& destination), travel time, travel cost and travel distance. The features of travelers (includes, age, occupation, and vehicle ownership), and travel behavior. The questions that address attitudes towards walking feeder mode choice for proposed integrated service of respondents were included only in the Stated Preference Survey and associated with demographic, socioeconomic and trip characteristics. Using RP and SP survey approach, a sum of 549 respondents' were interviewed and the respondents were requested to tell their preferable walking choice from proposed three services viz. Exclusive Sidewalk (ESW), Special Shoulder Treatment for Pedestrian only (SSTP) and Pedestrian allow in Mixed Traffic (PMT) services on 
Likert scales measurement (i.e. yes or no), by responding to a set of questions.

The Multinomial Logit (MNL) model was widely used to model the attributes and preferences of the respondents through their stated preference choices for both urban and intercity mode choice models due to its simple mathematical formulation, easy analysis, and interpretation. It was applied to the model attributes and the willingness of the respondents through their stated choice data sets. The MNL model estimated a utility function that determines outcome probabilities were more than two mode choices of travel are available for the users (Ashalatha et al., 2012). Logit models determine the probability that a node will be chosen based on comparison between individual utilities for each mode (Kumar and Electricwala, 2014). Therefore, the MNL model is used to analyze the respondents' attitudes towards walking feeder mode choice with the choice sets of ESW, SSTP and PMT services of BRTS corridor in the city of Ahmedabad. So, all relevant demographic, socioeconomic and trip/travel characteristic variables are incorporated in the model, and the coefficients are evaluated using maximum likelihood criterion. The MNL model briefly described as shown in Eq. (1) and Eq. (2):

$\operatorname{Pn}(\mathrm{i})=\frac{e^{(U i n)}}{\sum_{\mathrm{j}=1}^{\mathrm{M}} e^{(U j n)}}$

where: Pn (i)-Probability of individual n numbers choosing mode i; Ujn-Utility derived from individual $\mathrm{n}$ numbers from mode j; M-Set of all available transportation modes.

$U_{j n}=\alpha_{0} j+\left(\alpha_{1} j \times X_{1} n\right)+\left(\alpha_{2} j \times X_{2} n\right)+\ldots \ldots \ldots .+\left(\alpha_{n} j \times X_{q} n\right)$

where: $\alpha_{0} j, \alpha_{1} j, \alpha_{2} j, \ldots \ldots . ., \alpha_{n} j$-Coefficients correlated with explanatory variables; $X_{1} n, X_{2} n, \ldots \ldots . ., X_{q} n$-Explanatory variables for different n; q-Number of explanatory variables included in the model

\section{Case Study Area Profile}

Ahmedabad is the fifth largest city in the Gujarat state of India is selected for the present study. The city had a population of 5.5 million as per census 2011 with an area of $466 \mathrm{Sq}$. Km. In the city of Ahmedabad, our case study corridor of Viratnagar to Naroda Patiya is falling under two different zones name as East Zone and North Zone. The wardwise distribution of the survey area are Bapunagar $\left({ }^{*} \mathrm{~A}=2.28 \mathrm{Km}^{2}\right)$, Rakhiyal $\left(\mathrm{A}=3.06 \mathrm{Km}^{2}\right), \operatorname{Nikol}\left(\mathrm{A}=2.77 \mathrm{Km}^{2}\right)$ falling in East Zone and Asarwa $\left(\mathrm{A}=1.46 \mathrm{Km}^{2}\right)$, Naroda Road $\left(A=1.75 \mathrm{Km}^{2}\right)$, Saraspur $\left(A=1.69 \mathrm{Km}^{2}\right)$, Potaliya $\left(A=4.05 \mathrm{Km}^{2}\right)$, Kubernagar $\left(\mathrm{A}=2.33 \mathrm{Km}^{2}\right)$, Saijpur $(\mathrm{A}=$ $\left.2.15 \mathrm{Km}^{2}\right)$, Thakkarnagar $\left(\mathrm{A}=3.96 \mathrm{Km}^{2}\right)$, Naroda Muthiya $\left(\mathrm{A}=5.48 \mathrm{Km}^{2}\right)$ are falling under North Zone. As per the census 2011, the population of the Case study area is 0.9 million with a total area of $30.98 \mathrm{Sq} . \mathrm{km}$. The yellow hatched profiles in the study area shows walking feeder service area and the data samples are collected from this representative area only as illustrated in Fig. 3. 


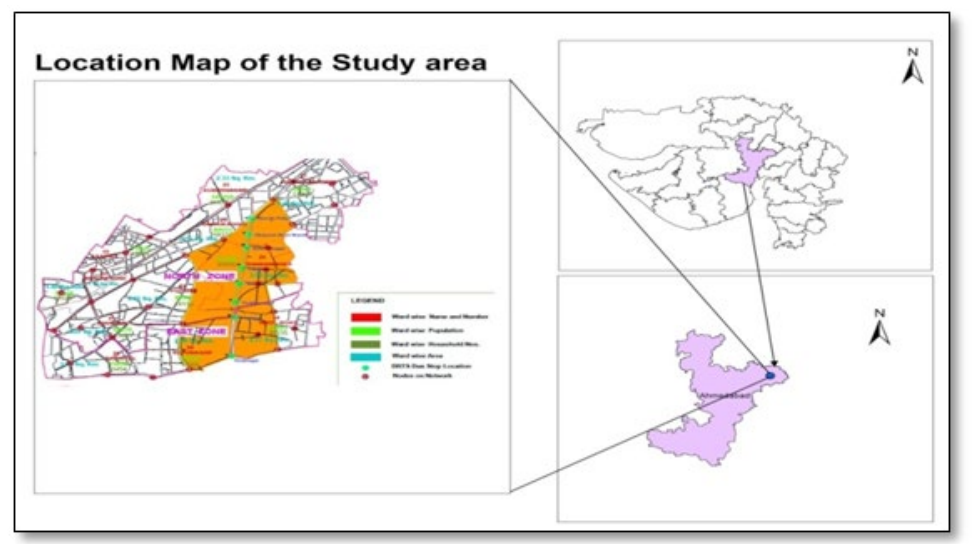

Fig. 3.

Study Area-Viratnagar to Naroda

\section{Model Specification and Data Analysis}

The pedestrian mode analysis of proposed integration for BRTS corridor in the city of Ahmedabad was considered. The socioeconomic and travel parameters were assessed as follows: The vehicle ownership was evaluated and assembles from 1 to 4 as (2W, Car, Bicycle and No Vehicle) and Household Size scale from 1 to $7(1,2,3,4,5$, 6 and 7). The Total Travel Time (TT) (access time + in vehicle time + egress time) divided on the scale as from 1 to 6 (0-15 min., 15-30 min., 30-45 min., 45-60 min., 60-90 min., and $>90 \mathrm{~min}$.). The travel distance added with access range + in vehicle distance+ egress distance with six categories from 1 to $6(<1 \mathrm{~km}, 1-2 \mathrm{~km}, 2-5 \mathrm{~km}, 5-10 \mathrm{~km}, 10-15$ $\mathrm{km}$ and $>15 \mathrm{~km})$. The attitudinal variables were categorized as follows: The three response variables (dependent variables) such as Exclusive Sidewalk (ESW), Special Shoulder Treatment for Pedestrian only (SSTP) and Pedestrian allow in Mixed Traffic (PMT) are categorized. Hence, these measured on Likert scales i.e. Accept or Reject the services. The independent (predictors) variables were categorized as household size, vehicle ownership, travel time and travel distance. The impacts and effects of these variables on the response variables are found out in this model. The variables represented in the coding system of Statistical Package for Social Science (SPSS) version 16.0 software for the present study.

The socioeconomic factors such as vehicle ownership, and household size are noticeably significant factors of the socioeconomic characteristics. The vehicle ownership result shows that $15 \%$ people have their car whereas $36 \%$ of people have $2 \mathrm{~W}$ which highest proportion of vehicle ownership. $22 \%$ people have bicycle whereas $27 \%$ have no vehicle which falls in under economically weaker sections and low-income groups. As per the survey, the household size observed as $29 \%$ households have six members per household while $24 \%$ have five members per households. Travel time analysis revealed 
that $33 \%$ people are traveling daily up to $31-45$ minutes while $24 \%$ respondents are daily travels to 60-90 minutes. Nearly 7\% people are daily travel more than 90 minutes while $13 \%$ people are travel less than 15 minutes per day. The travel distance related questionnaire revealed that $33 \%$ respondents have 5 to $10 \mathrm{~km}$ travel distance whereas $28 \%$ people have 2 to $5 \mathrm{~km}$ travel distance per day. It is observed that $7 \%$ people have $1 \mathrm{~km}$ whereas $11 \%$ have more than $15 \mathrm{~km}$ travel distance for daily.

\section{Results and Discussion}

The present study uses MNL (Multinomial Logit) model to scrutinize the relationships that exist between the socioeconomic factors (Household Size, Vehicle Ownership, Travel time and Travel Distance) and walking feeder mode services choice for proposed integrated service of BRTS study corridor in the city of Ahmedabad. It was carried out to identify the influence of various factors on the attitudinal behavior of the commuters towards proposed integrated walking feeder services. The idea to develop this model was to determine the choice of public transit users from the case study area and to grab the people from the farther away residential area towards the nearest BRTS bus stops to increase the ridership of public transit through proposed feeder service.

When using MNL regression model, one category of the dependent variable is selected as the reference category (here PMT service). It can also call as a standard class to which others (response category) would be compared logically. All the parameters in the model are input concerning this category. The coefficients are estimated through maximum likelihood method. All the variables obtained and presented had significant parameter estimates and logical signs.

The Likelihood ratio test specifies the contribution of the variables to the overall relationship between the dependent and independent variables in distinguishing between the sets specified by the dependent variable. The result shows that all the variables have significance less than 0.05 except HHS. So, it can be observed that the variables $\mathrm{VO}, \mathrm{TT}$, and $\mathrm{TD}$ have a significant contribution towards prediction of proposed walking feeder mode services. The input of each variable to the model by likelihood ratio test is explained as shown in Table 1.

Table 1

Likelihood Ratio Tests

\begin{tabular}{|c|c|c|c|c|}
\hline \multirow{2}{*}{ Effect } & Model Fitting Criteria & \multicolumn{3}{|c|}{ Likelihood Ratio Tests } \\
\cline { 2 - 5 } & $\begin{array}{c}\text {-2 Log Likelihood of } \\
\text { Reduced Model }\end{array}$ & Chi-Square & df & Sig. \\
\hline Intercept & 936.097 & 4.022 & 2 & - \\
\hline HHS & 932.780 & 0.705 & 2 & 0.703 \\
\hline VO & 935.694 & 10.619 & 2 & 0.012 \\
\hline TT & 932.100 & 27.025 & 2 & 0.016 \\
\hline TD & 933.482 & 14.407 & 2 & 0.008 \\
\hline
\end{tabular}


The coefficient $\mathrm{R}^{2}$ is interpreted in terms of the proportion of the total variation in 'dependent variable' which has "explained" by 'independent variables' and it is descriptive measure of the degree of linear association between independent and dependent variables which may or may not be useful any instance (Neter, 1983). The Cox and Snell $\mathrm{R}^{2}$ measure oblige like $\mathrm{R}^{2}$, with higher values indicating greater model fit. The Cox and Snell $\mathrm{R}^{2}$ (Ashalatha et al., 2012; Miskeen et al., 2013a) for this study are
0.510 , which indicates that model explains $51.0 \%$ of the variation in the dependent variables. The Nagelkerke $\mathrm{R}^{2}$ for the present study is 0.437 , which suggests that the model explains roughly $43.7 \%$ of the variation in the outcome. While, the $\mathrm{McF}$ adden $\mathrm{R}^{2}$ value is 0.394 which state $39.4 \%$ variation in the outcome. So, lastly based on the $\mathrm{R}^{2}$ value it can be concluded that the model explains nearly $39-51 \%$ variation in the study that is considered statistically significant result (as shown in Table 2).

\section{Table 2}

Pseudo R-Square

\begin{tabular}{|c|c|}
\hline Cox and Snell & 0.510 \\
\hline Nagelkerke & 0.437 \\
\hline McFadden & 0.394 \\
\hline
\end{tabular}

The classification accuracy rate usually should be 25 percent or more, higher than the proportional by chance accuracy rate (Bayaga, 2010; El-Habil, 2012; Wedagama, 2009). The proportional by chance accuracy rate can be computed by calculating the proportion of cases for each group based on the number of cases in each group of the response variable (Bayaga, 2010; El-Habil, 2012; Wedagama, 2009; White, 2013). The proportional by chance accuracy rate was figured by computing the proportion of each service category. It was computed by squaring and summing the proportion of cases in each group $\left(0.477^{2}\right.$ $\left.+0.357^{2}+0.166^{2}=0.383=38.3 \%\right)$. The proportional by chance accuracy criteria however was $47.9 \%(1.25 \times 38.3)$. The overall classification accuracy rate was $49.5 \%$ (cf. Table 3 ) which was greater than the proportional by chance accuracy criteria of $47.9 \%$, suggesting that the model was satisfied. The classification table of the present study is shown in Table 3.

Table 3

Classification Prediction Summary

\begin{tabular}{|c|c|c|c|c|}
\hline \multirow{2}{*}{ Observed } & \multicolumn{4}{|c|}{ Predicted } \\
\cline { 2 - 5 } & ESW & SSTP & PMT & Percent Correct \\
\hline ESW & 247 & 14 & 1 & $94.3 \%$ \\
\hline SSTP & 172 & 24 & 0 & $12.2 \%$ \\
\hline PMT & 87 & 4 & 0 & $0.0 \%$ \\
\hline Overall Percentage & $92.2 \%$ & $7.7 \%$ & $0.2 \%$ & $49.4 \%$ \\
\hline
\end{tabular}


The parameter estimates of each predictor for commuters' choice ESW to SSTP \& PMT represented in Table 4 respectively. B values represent the MNL regression coefficients for the developed models. The negative value of coefficients decreases the willingness of that response category to the given reference category. In this study, the third category (here PMT) of each predictor is taken as reference by default.

The Household Size (HHS) is the most important parameters for mode choice of any urban area. Unfortunately, and unexpectedly for the present study for both the dependent variables as ESW service and SSTP service, the coefficients show insignificant results. This could be due to the respondents not worry about their family size for the use of the service. Vehicle Ownership (VO) is noticeably an important factor affecting proposed walking feeder mode services choice as shown in Table 5. This research paper discovers some of the availability of personal vehicles in the household to find its effect on proposed feeder services; because the use of personal vehicles for their regular trips usually means that the private vehicle will be utilized for a whole period. The coefficients of Vehicle Ownership (VO) indicated statistically significant $(\mathrm{P}<0.05)$ which denote it contributed to the choice of walking feeder services. The estimated coefficients of VO for ESW and SSTP as walking feeder services were negative sign designates that most households do not have their personal vehicles so; they can make the service choice either ESW and SSTP as rather than the PMT service for proposed IPT service. This predicted model results emphasize closeness to the real scenario. The earlier literature also reported the similar results (Ashiabor et al., 2007; Miskeen et al., 2013b; Mukala and Chunchu, 2011).

Table 4

Parameter Estimates

\begin{tabular}{|c|c|c|c|c|c|c|c|}
\hline \multirow{2}{*}{\multicolumn{2}{|c|}{$\begin{array}{l}\text { Walking Feeder Mode } \\
\text { Services-Accept/Reject }\end{array}$}} & \multirow{2}{*}{ B } & \multirow{2}{*}{ df } & \multirow{2}{*}{ Sig. } & \multirow{2}{*}{$\operatorname{Exp}(\mathbf{B})$} & \multicolumn{2}{|c|}{ 95\% Confidence Interval for $\operatorname{Exp}(B)$} \\
\hline & & & & & & Lower Bound & Upper Bound \\
\hline \multirow{5}{*}{$\begin{array}{c}\text { Exclusive Sidewalk } \\
\text { (ESW) }\end{array}$} & Intercept & 0.838 & 1 & - & - & - & - \\
\hline & HHS & -0.075 & 1 & 0.499 & 0.927 & 0.745 & 1.154 \\
\hline & $\mathrm{VO}$ & -0.220 & 1 & 0.026 & 0.803 & 0.638 & 1.009 \\
\hline & TT & -0.131 & 1 & 0.012 & 1.013 & 0.860 & 1.193 \\
\hline & TD & -0.192 & 1 & 0.008 & 1.105 & 0.918 & 1.330 \\
\hline \multirow{5}{*}{$\begin{array}{l}\text { Special Shoulder } \\
\text { Treatment for } \\
\text { Pedestrian } \\
\text { (SSTP) }\end{array}$} & Intercept & 0.566 & 1 & - & - & - & - \\
\hline & HHS & -0.016 & 1 & 0.137 & 0.984 & 0.784 & 1.236 \\
\hline & VO & -0.184 & 1 & 0.033 & 0.832 & 0.656 & 1.055 \\
\hline & TT & -0.127 & 1 & 0.043 & 1.012 & 0.853 & 1.200 \\
\hline & TD & -0.141 & 1 & 0.010 & 1.117 & 0.921 & 1.355 \\
\hline
\end{tabular}


Models, Eq. (3) and Eq. (4):

${ }^{*} P_{E S W}=0.838-0.075(H H S)-0.213(V O)-0.131(T T)-0.192(T D)$

$P_{S S T P}=0.566-0.016(H H S)-0.184(V O)-0.127(T T)-0.141(T D)$

where: ${ }^{*} \mathrm{P}=$ Probability of choosing particular service

The level of service variables, such as Travel Time (TT) and Travel Distance (TD) is usually expected to have negative signs coefficients. As both TT and TD increase, the probability of selecting the modes will decrease. As expected, they had the negative sign. It can be observed that $\mathrm{TT}$ and $\mathrm{TD}$ increases, the chance to use proposed walking feeder services will decrease and the users may shift to personal vehicles to reach the nearest bus stops. Past literature studies have considered travel time and travel distance to have substantial undesirable effects on the travel mode choice (i.e. travelers always prefer for lesser time and distance modes). The models developed for the present study for ESW and SSTP is shown in Eq. (3) and Eq. (4).

\section{Conclusion}

In developing Asian Countries, there is a large section of the society of users prevents from using the public transit due to the lack of accessibility to public transit stops. Pedestrian has to cope up with this problem by improving the public transportation or providing integrated service to the public transit stops. The objective of this research paper is to introduce the integrated walking feeder mode services and to develop the choice service modeling for BRTS corridor in the city of Ahmedabad.
The pseudo $\mathrm{R}^{2}$ value of the model according to the Cox and Snell is the model explains 0.510 indicating $51.0 \%$ of the variation in the dependent variables. While Nagelkerke $R^{2}$ is 0.437 , which suggests that the model explains roughly $43.7 \%$ of the variation in the outcome. The overall $\mathrm{R}^{2}$ value observation suggests that the model explains nearly $39-51 \%$ difference in the present study which is considered statistically significant result. Income wise comparison revealed that increasing income per month the users are more likely to prefer ESW and SSTP services compared with PMT service for their commuting travel because of less safety in mixed traffic service. The observation of vehicle ownership is designated that most households do not have their personal vehicles. It is more likely prefer the choice of either ESW and SSTP service about the PMT service. With the increase in Travel Time (TT) and Travel Distance (TD), the probability of the commuters' preference towards services decrease and the users may want to shift to personal vehicles to reach the nearest bus stops. The prediction success of available overall accuracy found $49.4 \%$ which indicated nearly good result is the final results of this paper. To sum up the output of this research, the developed mathematical models can apply to the policy makers for BRT system of Ahmedabad city by the integrated walking feeder mode services to maximize the utility and the ridership of this scheme.

\section{References}

Ashalatha, R.; Manju, V.; Zacharia, A.B. 2012. Mode Choice Behavior of Commuters in Thiruvananthapuram City, Journal of Transportation Engineering 139(5): 494-502. 
Ashiabor, S.; Baik, H.; Trani, A. 2007. Logit Models for Forecasting Nationwide Intercity Travel Demand in the United States, Transportation Research Record: Journal of the Transportation Research Board: 1-12.

Balya, M.I.; Kumar, R. 2017. Proposed Integrated Bicycle Feeder Mode Service Analysis for Bus Rapid Transit System-A Multinomial Logit Model Approach, International Journal for Traffic and Transport Engineering 7(1): 108-116.

Bayaga, A. 2010. Multinomial Logistic Regression: Usage and Application in Risk Analysis, Journal of applied quantitative methods 5(2): 288-297.

Cervero, R. 2001. Walk-And-Ride: Factors Influencing Pedestrian Access to Transit, Journal of Public Transportation 7(3): 1-23.

Chandra, S.; Bari, M.E.; Devarasetty, P.C.; Vadali, S. 2013. Accessibility Evaluations of Feeder Transit Services, Transportation Research Part A: Policy and Practice 52: 47-63.

Chien, S.; Yang, Z. 2000. Optimal Feeder Bus Routes on Irregular Street Networks, Journal of Advanced Transportation 34(2): 213-248.

Das, S.S.; Maitra, B.; Boltze, M. 2012. Planning of FixedRoute Fixed-Schedule Feeder Service to Bus Stops in Rural India, Journal of Transportation Engineering 138(10): 1274-1281.

El-Habil, A.M. 2012. An Application on Multinomial Logistic Regression Model, Pakistan Journal of Statistics and Operation Research 8(2): 271-291.

Kumar, R.; Electricwala, F. 2014. Impact of Proposed Modal Shift from Private Users to Bus Rapid Transit System: An Indian City Case Study, International Journal of Civil, Environmental, Structural, Construction and Architectural Engineering 8(6):663-667.
Loutzenheiser, D. 1997. Pedestrian Access to Transit: Model of Walk Trips and Their Design and Urban Form Determinants Around Bay Area Rapid Transit Stations, Transportation Research Record: Journal of the Transportation Research Board 1604: 40-49.

Martínez, L.M. Eiró, T. 2012. An Optimization Procedure to Design a Minibus Feeder Service: An Application to the Sintra Rail Line, Procedia-Social and Behavioral Sciences 54: 525-536.

Miskeen, A.; Alhodairi, A.M.; Rahmat, R. 2013a. Modeling a Multinomial Logit Model of Intercity Travel Mode Choice Behavior for All Trips in Libya, International Journal of Civil, Architectural Science and Engineering 7(9): 1-10.

Miskeen, A.; Manssour, A.; Mohamed Alhodairi, A.; Rahmat, R. 2013b. Modeling of Intercity Transport Mode Choice Behavior in Libya: a Binary Logit Model for Business Trips by Private Car and Intercity Bus, Australian Journal of Basic \& Applied Sciences 7(1): 302-311.

Mohaymany, A.S.; Gholami, A. 2010. Multimodal Feeder Network Design Problem: Ant Colony Optimization Approach, Journal of Transportation Engineering 136(4): 323-331.

Mukala, P.K.; Chunchu, M. 2011. Mode Choice Modelling for Intercity Transportation in India: A Case of Guwahati to Five Metro Cities, International Journal of Earth Sciences and Engineering 4(6): 364-374.

Neter, J. 1983. Applied Linear Regression Models. R.D. Irwin-Open Library.

Polzin, S.; Chu, X.; Rey, J. 2000. Density and Captivity in Public Transit Success: Observations from the 1995 Nationwide Personal Transportation Study, Transportation Research Record: Journal of the Transportation Research Board (1735): 10-18. 
Rahman, M. S.-U.; Timms, P.; Montgomery, F. 2012. Integrating BRT Systems With Rickshaws in Developing Cities to Promote Energy Efficient Travel, Procedia-Social and Behavioral Sciences 54:261-274.

Replogle, M. 1992. Bicycles and Cycle-Rickshaws in Asian Cities: Issues and Strategies, Transportation Research Record 1372: 76-84.

Rudnicki, A. Equivalent Travel Time of Passengers as a Synthetic Performance Measure in Urban Public Transport. In Proceedings from the $2^{\text {nd }}$ KFB-Research Conference on Urban Transport Systems, 174-183.

Shrivastava, P.; O'Mahony, M. 2006. A Model for Development of Optimized Feeder Routes and Coordinated Schedules-A Genetic Algorithms Approach, Transport policy 13(5): 413-425.

Stringham, M. 1982. Travel Behavior Associated with Land Uses Adjacent to Rapid Transit Stations, Institute of Transportation Engineers Journal 52(4): 18-22.
Verma, A.; Dhingra, S. 2005. Feeder Bus Routes Generation within Integrated Mass Transit Planning Framework, Journal of Transportation Engineering 131(11): 822-834.

Wedagama, D.P. 2009. A Multinomial Logit Model for Estimating the Influence of Household Characteristics on Motorcycle Ownership: A Case Study in Denpasar City, Bali, Journal of Civil Engineering 29(1): 2-9.

White, J. 2013. Logistic Regression Model Effectiveness: Proportional Chance Criteria and Proportional Reduction in Error, Journal of Contemporary Research in Education 2(1): 4-10.

Wibowo, S.S.; Olszewski, P. 2005. Modeling Walking Accessibility to Public Transport Terminals: Case Study of Singapore Mass Rapid Transit, Journal of the Eastern Asia Society for Transportation Studies 6: 147-156.

\section{ijtte 497}

